\title{
A Multiplex Assay for Simultaneous Detection of Three Retroviruses in Nonhuman Primates Based on the Luminex xTAG Platform
}

\author{
Zhu-hong Liu ${ }^{1,2,3}$, Ling Tang ${ }^{1},{ }^{2}$, Xian-Xu Liu ${ }^{1},{ }^{2}$, Jing Wang $^{3}$, Yu-jun Zhu ${ }^{3}$, Xue-qin Yin ${ }^{3}$, Yu Zhang ${ }^{3}$, Ren Huang $^{3 *}$ \\ ${ }^{1}$ Guangdong polytechnic of Science and Trade, No.388 Shiqing Road, Guangzhou, Guangdong, 510430, China \\ ${ }^{2}$ Guangdong Provincial Key Lab of Pathogenic Biology and Epidemiology for Aquatic Economic Animals, No.1 Haida Road, \\ Zhanjiang, Guangdong, 524088, China \\ ${ }^{3}$ Guangdong Provincial Key Laboratory of Laboratory Animal; Guangdong Laboratory Animals Monitoring Institute; No.11 Fengxin \\ Road, Guangzhou, Guangdong, 510663, China
}

\begin{abstract}
Article History
Received: 11.03.2021

Accepted: 14.04.2021

Published: 20.04 .2021

Journal homepage:

https://www.easpublisher.com

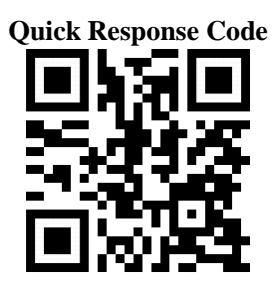

Abstract: Nonhuman primates (NHPs) are widely used for investigating retroviral pathogenesis. Before experiments are conducted and breeding programs established, the animals must be judged negative for endogenous retroviruses. We developed a multiplex high-throughput detection method using multiplexed Luminex fluorescent microbeads and the xTAG system (MMxTAG). We tested three retroviral DNA detection assays for use in a single tube reaction by taking advantage of the Luminex xTAG platform. The assay showed a high sensitivity that was comparable to $\mathrm{qPCR}$ methods. The detection limits approached 1-10 $\mathrm{fg} / \mu \mathrm{L}$ of plasmid DNA. We compared the specificity, efficiency and accuracy with ELISA assays and found our assay was superior in all regards. The MMxTAG performed well with clinical specimens and could selectively detect a single virus in the presence of the other two. This MMxTAG procedure can be applied to pathogen monitoring in animals and is present in a high throughput format that has low operating and development costs for protecting monkey contacts against these infectious diseases.
\end{abstract}

Keywords: Nonhuman primates; Luminex xTAG®; retroviruses.

Copyright (C) 2021 The Author(s): This is an open-access article distributed under the terms of the Creative Commons Attribution 4.0 International License (CC BY-NC 4.0) which permits unrestricted use, distribution, and reproduction in any medium for non-commercial use provided the original author and source are credited.

\section{INTRODUCTION}

Nonhuman primates (NHPs) are critical to many biomedical research programs due to their similarities to humans [1-3]. Macaques used in preclinical studies were previously caught in the wild and harbored their natural microflora as well as pathogenic bacteria, viruses, parasites and fungi [4]. These animals are now bred in captivity for use in biomedical research programs [5]. However, the animals may still harbor novel infectious agents that can result in high morbidity and mortality as they did in wild populations [6].

Microbial surveillance programs have made much progress in excluding select pathogens from these animal colonies [6, 7]. However, simian immunodeficiency virus (SIV), simian type D retrovirus (SRV) and simian T-cell lymphotropic virus (STLV) are still present and pose significant risks to the animals as well as laboratory personnel. This is especially true in the case of developing specific-pathogen free (SPF) animals [7]. Therefore, we establish and maintain SPF colonies with the goals of improving animal health and reproduction by elimination of potential animal pathogens to (i) avoid the interference of these pathogens in biomedical research and (ii) reduce or eliminate potential sources of human occupational exposure to selected NHP viruses.

The normal laboratory procedures for detecting SIV, SRV and STLV-1 is culture in CM-174, Raji or MT-4 cells followed by immunohistochemical and immunofluorescence assays for virus identification [810]. ELISA or immunofluorescence assays (IFA) are required methods for excluding these pathogens in the course of selecting and monitoring SPF NHPs [11, 12]. New molecular techniques such as PCR, qPCR, high resolution melting (HRM) analysis and next generation sequencing (NGS) have made these viral screens routine. They are now incorporated into disease surveillance programs $[13,6,14,7,15]$. These techniques also have the potential to identify novel and uncharacterized pathogens in these laboratory animals.

Microbead-based liquid arays are widely used for antigen detection due to their relative ease of use, 
small sample volumes and multiplex platforms. Luminex microspheres have been the industry standard for microbead fluidics and the xMAP technology enables antigen capture on beads containing unique spectral addresses for up to 500 antigens simultaneously [16-20]. We have developed a Luminex xTAG assay for the simultaneous detection of three retroviruses that infect non-human primates. At the same time, it could be used more conveniently instead of PCR in the confirmatory assays, and more, it could detect the endogenous viruses to discern the false negative in ELISA assays.

\section{MATerials ANd Methods}

Ethical approval: All procedures performed in this study were in accordance with the ethical standards of IACUC of Guangdong Laboratory Animals Monitoring Institute which was certified by AAALAC.

Viruses and RNA extraction: SIV and SRV1-3 were cultured in CM-174 cell and Raji cell lines, respectively. RNA was extracted with Trizol reagent (Takara, Dalian). SIVcDNA and SRVcDNA were gained by reverse transcription with kit (Takara, Dalian). One of STLV-1 DNA was extracted from the ELISA-positive simian and the other named XS001 was purchased from Suzhou Xishan Biotechnology Inc., Suzhou).

Primers design: PCR primers for detection of individual viruses were designed using standard PCR conditions to generate $\sim 200 \mathrm{bp}$ amplicons (Table 1). These primers amplified SIV gag, SRV p27 and STLV1 env genes. A highly conserved region of the Simian actin gene (Genbank: NM_001033084) was used as an internal control for identification of simian species as previously described [15]. Coupling of DNA to the microspheres used a commercial kit (Luminex) following the procedure provided by the manufacturer. The sequences of the primers and XTAG sequences are shown in Table 1. Primers were synthesized by Shenggong Biotechnology (Shanghai, China).

MMxTAG Protocol: (1) PCR amplification. Multiplex PCR reactions for amplification of the SIVgag, SRV p27 and STLV-1 env genes were carried out using a commercial PCR kit following instructions provided by the manufacturer (Qiagen, Shanghai,China). The mixture contained $1 \times$ reaction master mix, $0.2 \mu \mathrm{M}$ of each of the XTAG and biotinylated primers and $2.0 \mu \mathrm{L}$ template. The PCR amplification program was $95{ }^{\circ} \mathrm{C}$ for $5 \mathrm{~min}$; 33 cycles of $95{ }^{\circ} \mathrm{C}$ for $30 \mathrm{~s}, 58{ }^{\circ} \mathrm{C}$ for $30 \mathrm{~s}$, and $72{ }^{\circ} \mathrm{C}$ for $30 \mathrm{~s}$; followed by a final elongation step at $72{ }^{\circ} \mathrm{C}$ for $5 \mathrm{~min}$. (2) Hybridization. Luminex MagPlex-xTAG microspheres (Luminex, Shanghai, China) were equilibrated to room temperature, vortexed for 20 s and then sonicated for 10s. Four different MagPlex-xTAG microspheres with different anti-xTAG sequences were diluted to have 50 of each microsphere set per $\mu \mathrm{L}$ in sterilized $1 \times$ Tm Hybridization Buffer $(0.2 \mathrm{M} \mathrm{NaCl}$, $0.1 \mathrm{M}$ Tris, $0.08 \%$ Triton $\mathrm{X}-100, \mathrm{pH}$ 8.0). The mixture was prepared so that 1000 microspheres of each set were contained in each reaction. Streptavidin and RPhycoerythrin Conjugate (SAPE, Invitrogen, Carlsbad, $\mathrm{CA}$, USA) was diluted to $1 \mu \mathrm{g} / \mathrm{ml}$ in $1 \times \mathrm{Tm}$ Hybridization Buffer. For each hybridization reaction $20 \mu \mathrm{L}$ MagPlex-TAG microspheres (Luminex, Shanghai, China), $5 \mu \mathrm{L}$ of each PCR reaction (or $\mathrm{H}_{2} \mathrm{O}$ control) and $75 \mu \mathrm{L}$ of reporter solution (Luminex, Shanghai, China) were combined and the mixture was hybridized at $45^{\circ} \mathrm{C}$ for $30 \mathrm{~min}$. (3) Signal detection. Hybrid complexes were analyzed for each bead type and the fluorescence intensity (MFI) was measured using a Luminex 200 instrument and analyzed using XPONENT 3.1 software included with the instrument (Luminex). The sample volume was set to $60 \mu \mathrm{L}$ with a minimum of 100 beads per target with a gate of 7500 to 13500, and the plate heater was adjusted to the hybridization temperature, $45^{\circ} \mathrm{C}$. The background reactions included all reaction components except that an equal volume of water replaced the DNA. The MFI of a positive signal was defined as four times the reference negative.

The evaluation of sensitivity and specificity: Sensitivity and specificity was determined by cloning the tagged PCR amplicons from each gene into plasmid vector pMD19-T. Recombinant plasmids were introduced into Escherichia coli strain DH5aby transformation for the production of pure plasmid DNA. Plasmids were serially diluted and coupled to beads as outlined above. These served as quantification standards. Specificity was determined by using nonmatching templates in control reactions.

Compared with ELISA: Nineteen blood samples were collected and DNA was extracted from whole blood using a commercial kit (Tiangen Biotech co.LTD., Beiing). Serum from the samples was used for comparative analysis using a commercial ELISA kit (Xishan Biotechnology).

Application to clinical samples: Clinical samples were collected from the simian-bred farms, precursor genomic DNA was extracted with a commercial kit (Tiangen Biotech co.LTD., Beiing), then was analyzed with MMxTAG platform.

\section{RESULTS}

Analytical sensitivity and specificity: We initially tested the quality of our detection method by adding single template test NA to the Luminex bead triplex reaction mixture. We achieved sensitivities approaching 100ag/uL using the triplexed beads. A mixture of all three plasmid DNAs gave detection sensitivities approximately 1fg/uL (Fig. 1). Control electrophoretogram of multiplex PCR products revealed 
results similar to these (Fig. 2). When the Luminex reaction mixtures contained only a single specificity bead, the sole positive MFI value was that of the corresponding added DNA. When the cDNAs were mixed and added to the triplex reaction, all cDNAs could successfully be detected without interference from the others (Table 2).

Comparison of MMxTAG and ELISA for detection of three retroviruses: We performed blind testing and compared the MMxTAG and ELISA procedures for nineteen Simian blood samples (Table 3 ). The majority of samples were negative by both methods with three exceptions: Sample DWBSIV was SIV positive and samples 0921930C and 0922906C were STLV positive. However, the latter sample (0922906C) was also SIV positive only with the ELISA procedure. This sample was judged negative by qPCR (data not shown).

Application to clinical specimens: We next examined thirty-nine clinical whole blood specimens containing EDTA as anticoagulant. These had all been previously determined to be negative by ELISA by the animal facility laboratory. The samples from two different primate colonies were collected and used for DNA extraction. We found two positive STLV samples and the findings were corroborated by qPCR (data not shown). Two positive control samples (DWBSIV and DWBSRV) that had been previously infected with SIV and SRV, respectively, were determined positive. The control STLV DNA (sample XS001) was determined negative (Table 4).

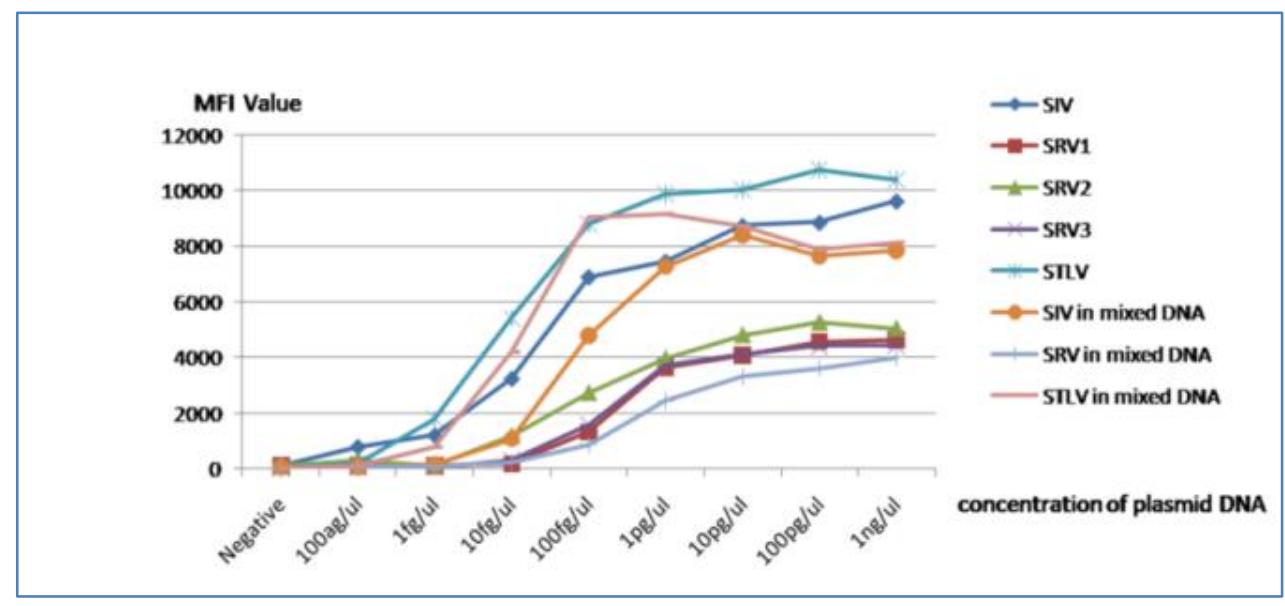

Fig-1: The sensitivities of the single plasmid DNA and mixed DNA of SIV/SRV/STLV
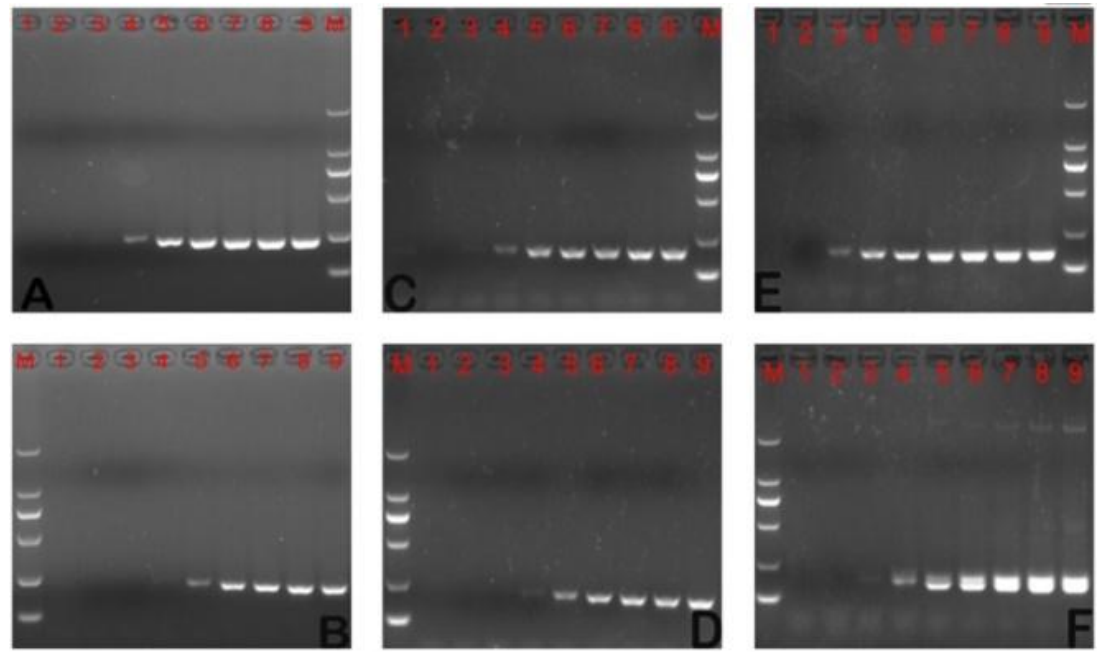

Fig-2: The electrophoretogram of multiplex PCR products

A- plasmid DNA of SIV, B- plasmid DNA of SRV1, C- plasmid DNA of SRV2, D- plasmid DNA of SRV3, Eplasmid DNA of STLV, F-mixed plasmid DNA of SIV/SRV1/SRV2/SRV3/STLV 
Table-1: PCR primers designed for SIV, SRV, STLV and Simian actin gene

\begin{tabular}{|l|l|l|}
\hline Luminex xTAG Bead No. & Primers & $\begin{array}{l}\text { Sequence (5'-3') } \\
\text { ATC }\end{array}$ \\
\hline \multirow{2}{*}{15} & SIV-tagF & $\begin{array}{l}\text { ATCAATTACAATAACACACAAA-spacer18- } \\
\text { ACGACCCGGCGGAAAGAAAAGT }\end{array}$ \\
\cline { 2 - 3 } & SIV-tagR & Biotinylated-TGCACCAGATGACGCAGACAGT \\
\hline 56 & SRV-tagF & $\begin{array}{l}\text { TACTTCTTTACTACAATTTACAAC-spacer18- } \\
\text { AYGGGGCTACTGCYCCATA }\end{array}$ \\
\cline { 2 - 3 } & SRV-tagR & Biotinylated-GCCATTACCKGCYTGTTGATT \\
\hline 19 & STLV-tagF & $\begin{array}{l}\text { CTTAAACTCTACTTACTTCTAATT-spacer18- } \\
\text { GTGCCAATCATGGACCTGCC }\end{array}$ \\
\cline { 2 - 3 } & STLV-tagR & Biotinylated-TCCTGGAGCGTCGATTAGAAGG \\
\hline & Actin-tagF & $\begin{array}{l}\text { ATACTTTACAAACAAATAACACAC-spacer18- } \\
\text { CCTCCCTGGAGAAGAGCTACGA }\end{array}$ \\
\cline { 2 - 3 } & Actin-tagR & Biotinylated-ATGCCACAGGACTCCATGCC \\
\hline
\end{tabular}

a: The sequences that are italicized and underlined are anti-xTAG sequences

Table-2: Specificity of single- and multiple-specificity of xTAG beads

\begin{tabular}{|c|c|c|c|c|c|c|c|c|}
\hline \multirow{2}{*}{$\begin{array}{c}\text { Bead NO. } \\
\text { Target }\end{array}$} & \multicolumn{4}{|c|}{ single xTAG bead } & \multicolumn{4}{|c|}{ Multiple xTAG beads } \\
\hline & $\begin{array}{l}\text { 67(SI } \\
\text { V) }\end{array}$ & $\begin{array}{l}\text { 15(S } \\
\text { RV) }\end{array}$ & $\begin{array}{l}56(S \\
\text { TLV } \\
)\end{array}$ & $\begin{array}{l}19(A) \\
\text { ctim })\end{array}$ & 67(SIV) & $\begin{array}{l}\text { 15(SR } \\
\text { V) }\end{array}$ & $\begin{array}{l}56(S \\
\text { TLV } \\
\text { ) }\end{array}$ & $\begin{array}{l}\text { 19(Acti } \\
\text { m) }\end{array}$ \\
\hline Water & $-{ }^{b}$ & - & - & - & - & - & - & - \\
\hline SIV cDNA & $+^{\mathrm{c}}$ & - & - & + & + & - & - & + \\
\hline SRV1 cDNA & - & + & - & + & - & + & - & + \\
\hline SRV2 cDNA & - & + & - & + & - & + & - & + \\
\hline SRV3 cDNA & - & + & - & + & - & + & - & + \\
\hline STLV DNA & - & - & + & + & - & - & + & + \\
\hline Mixed DNA $^{\mathrm{d}}$ & + & + & + & + & + & + & + & + \\
\hline Genomic DNA $^{\mathrm{e}}$ & - & - & - & + & - & - & - & + \\
\hline
\end{tabular}

b: Negative (-); c: Positive (+); d: Mixed DNA was mixed with SIVcDNA, SRVcDNA and STLV DNA; e: Genomic DNA from the blood of a SPF simian.

Table-3: A comparison of ELISA and MMxTAG procedures for detecting SIV, SRV and STLV in blood samples

\begin{tabular}{|c|c|c|c|c|c|c|}
\hline \multirow{2}{*}{$\begin{array}{l}\text { Sample } \\
\text { Name }\end{array}$} & \multicolumn{2}{|l|}{ SIV } & \multicolumn{2}{|l|}{ SRV } & \multicolumn{2}{|l|}{ STLV } \\
\hline & ELISA & MМхTAG & ELISA & MMxTAG & ELISA & MMxTAG \\
\hline BS001 & - & - & - & - & - & - \\
\hline BS002 & - & - & - & - & - & - \\
\hline BS003 & - & - & - & - & - & - \\
\hline BS004 & - & - & - & - & - & - \\
\hline BS005 & - & - & - & - & - & - \\
\hline BS006 & - & - & - & - & - & - \\
\hline BS007 & - & - & - & - & - & - \\
\hline BS008 & - & - & - & - & - & - \\
\hline BS009 & - & - & - & - & - & - \\
\hline BS010 & - & - & - & - & - & - \\
\hline BS011 & - & - & - & - & - & - \\
\hline BS012 & - & - & - & - & - & - \\
\hline BS013 & - & - & - & - & - & - \\
\hline BS014 & - & - & - & - & - & - \\
\hline BS015 & - & - & - & - & - & - \\
\hline 0921930C & - & - & - & - & + & + \\
\hline 0922906C & + & - & - & - & + & + \\
\hline XS001 & - & - & - & - & $\mathrm{ND}^{\mathrm{f}}$ & - \\
\hline DWBsiv & + & + & - & - & - & - \\
\hline
\end{tabular}

f: Not determined. 
Table-4: Results of clinical specimen testing by MMxTAG

\begin{tabular}{|l|l|l|l|l|l|l|l|l|l|}
\hline Sample & actin & SRV & STLV & SIV & Sample & actin & SRV & STLV & SIV \\
\hline CS1 & + & - & - & - & CS24 & + & - & - & - \\
\hline CS2 & + & - & - & - & CS25 & + & - & - & - \\
\hline CS3 & + & - & - & - & CS26 & + & - & - & - \\
\hline CS4 & + & - & - & - & CS27 & + & - & - & - \\
\hline CS5 & + & - & - & - & CS28 & + & - & - & - \\
\hline CS6 & + & - & - & - & SC1 & + & - & + & - \\
\hline CS7 & + & - & - & - & SC2 & + & - & - & - \\
\hline CS8 & + & - & - & - & SC3 & + & - & - & - \\
\hline CS9 & + & - & - & - & SC4 & + & - & - & - \\
\hline CS10 & + & - & - & - & SC5 & + & - & - & - \\
\hline CS11 & + & - & - & - & SC6 & + & - & - & - \\
\hline CS12 & + & - & - & - & SC7 & + & - & - & - \\
\hline CS13 & + & - & - & - & SC8 & + & - & - & - \\
\hline CS14 & + & - & - & - & SC9 & + & - & - & - \\
\hline CS15 & + & - & - & - & SC11 & + & - & - & - \\
\hline CS16 & + & - & - & - & SC12 & + & - & + & - \\
\hline CS17 & + & - & - & - & DWBSIV & + & - & - & + \\
\hline CS18 & + & - & - & - & DWBSRV & + & + & - & + \\
\hline CS19 & + & - & - & - & XS001 & + & - & - & - \\
\hline CS20 & + & - & - & - & H2O & - & - & - & - \\
\hline CS21 & + & - & - & - & plasmid & ND & + & + & + \\
\hline CS22 & + & - & - & - & $\begin{array}{l}\text { DNA } \\
\text { mixture }\end{array}$ & + & + & + & + \\
\hline CS23 & + & - & - & - & Blank & - & - & - & - \\
\hline
\end{tabular}

g: Water control sample.

\section{DISSCUSSION}

In this study, we established a multiplex assay for the simultaneous detection of three retroviruses based on Luminex xTAG platform, and evaluated its performance with clinical specimens. The MMxTAG assay has been previously shown to be pathogenspecific and with sensitivity equal to or exceeding PCR or qPCR procedures [21, 19]. The assay accuracy was improved due to the greater sample sizes using the MFI of individual beads, allowing for greater statistical significance. This assay also allows for simultaneous detection of multiple nucleic acid sequences in a single reaction, and saves time while lowering the cost and work associated with single tube detection [22]. Moreover, it solves the shortcoming that traditional multiplex PCR presents in the design of different sized amplification fragments. In addition, the Luminex assay has been tested with up to 100 different templates in a single reaction tube that will lead to more advances in high-throughput detection [23]. Multiplex PCR coupled to the Luminex xTAG platform is currently in place for pathogen detection, SNP genotyping and disease screening [24, 25]. There is a multiplex micro-bead immunoassay (MMIA) as an alternative to PCR for detecting up to six viruses in primates using antibody detection. The assay has a greater sensitivity than ELISA does but the bead-coupling procedure to recombinant viral antigens and synthetic viral peptides greatly increased the assay cost $[16,18]$.
Identical volumes of sample and mixed plasmid DNA were used in each test, which was equivalent to a four-fold dilution. Therefore, the sensitivity of a single test was greater than the quadruplex detection for the plasmid DNA in our experiments. Interestingly, the control STLV DNA we purchased gave a negative result and we cannot currently account for this. However, only two clinical samples were detected as STLV-positive and this result was consistent with previous findings using these same samples [26].

\section{Conclusions}

In China, with the continuous development of simian breeding programs, the management level is becoming standardized and many enterprises have their own quarantine facilities and personnel. Therefore, a rapid method for the determination of viral infections can screen out infected animals before they are subjected to a lengthy quarantine process. Given that ELISA results may include false positives, the MMxTAG method can be a favorable addition to their testing procedures while saving time and money and protect monkey contacts against these infectious diseases. We developed a multiplex PCR-based on Luminex xTAG platform that is a high-throughput, sensitive and specific method that can be easily adapted to any animal laboratory. 


\section{ACKNOWLEDGEMENTS}

The study was funded by the Research Fund Program of Guangdong Provincial Key Lab of Pathogenic Biology and Epidemiology for Aquatic Economic Animals[PBEA2020YB06], the Education Department of Guangdong Province[2018GkQNCX069] and the Ministry of Science and Technology Project [grant numbers: 2015BAI07B01].

\section{Author's contribution}

ZH L, L T, XX L, J W, YJ Z, and XQ Y made substantial contributions to conception and design, or acquisition of data, or analysis and interpretation of data. ZH L was involved in drafting the manuscript or revising it critically for important intellectual content. Y $\mathrm{Z}$ and $\mathrm{R} \mathrm{H}$ gave final approval of the version submitted for publishing. All authors read and approved the final manuscript.

\section{REFERENCES}

1. Smith, D. R., Bird, B. H., Lewis, B., Johnston, S. C., McCarthy, S., Keeney, A., ... \& Hensley, L. E. (2012). Development of a novel nonhuman primate model for Rift Valley fever. Journal of virology, 86(4), 2109-2120.

2. Jensen, K., Ranganathan, U. D. K., Van Rompay, K. K., Canfield, D. R., Khan, I., Ravindran, R., ... \& Abel, K. (2012). A recombinant attenuated Mycobacterium tuberculosis vaccine strain is safe in immunosuppressed simian immunodeficiency virus-infected infant macaques. Clinical and Vaccine Immunology, 19(8), 1170-1181.

3. Engel, G., Wilbur, A. K., \& Jones-Engel, L. (2013). How well do you know your monkey TB model?. Journal of medical primatology, 42(1), 46.

4. Sasseville, V. G., \& Mansfield, K. G. (2010). Overview of known non-human primate pathogens with potential to affect colonies used for toxicity testing. Journal of immunotoxicology, 7(2), 79-92.

5. Vassall, A., van Kampen, S., Sohn, H., Michael, J. S., John, K. R., den Boon, S., ... \& Cobelens, F. (2011). Rapid diagnosis of tuberculosis with the Xpert MTB/RIF assay in high burden countries: a cost-effectiveness analysis. PLoS Med, 8(11), e1001120.

6. Bailey, C., \& Mansfield, K. (2010). Emerging and reemerging infectious diseases of nonhuman primates in the laboratory setting. Veterinary pathology, 47(3), 462-481.

7. Mansfield, K. G., Sasseville, V. G., \& Westmoreland, S. V. (2014). Molecular localization techniques in the diagnosis and characterization of nonhuman primate infectious diseases. Veterinary pathology, 51(1), 110-126.

8. GARDNER, M. B., LUCIW, P., LERCHE, N., \& MARX, P. (1988). Nonhuman primate retrovirus isolates and AIDS. Advances in veterinary science and comparative medicine, 32, 171-226.

9. Hirsch, V. M., Dapolito, G., Johnson, P. R., Elkins, W. R., London, W. T., Montali, R. J., ... \& Brown, C. (1995). Induction of AIDS by simian immunodeficiency virus from an African green monkey: species-specific variation in pathogenicity correlates with the extent of in vivo replication. Journal of virology, 69(2), 955-967.

10. Liégeois, F., Lafay, B., Switzer, W. M., Locatelli, S., Mpoudi-Ngolé, E., Loul, S., ... \& Peeters, M. (2008). Identification and molecular characterization of new STLV-1 and STLV-3 strains in wild-caught nonhuman primates in Cameroon. Virology, 371(2), 405-417.

11. Zuber, B., Quigley, M. F., Critchfield, J. W., Shacklett, B. L., Abel, K., Miller, C. J., ... \& Sandberg, J. K. (2006). Detection of macaque perforin expression and release by flow cytometry, immunohistochemistry, ELISA, and ELISpot. Journal of immunological methods, 312(1-2), 45-53.

12. Montiel, N. A., Todd, P. A., Yee, J., \& Lerche, N. W. (2012). Effects of simian betaretrovirus serotype 1 (SRV1) infection on the differentiation of hematopoietic progenitor cells (CD34+) derived from bone marrow of rhesus macaques (Macaca mulatta). Comparative medicine, 62(1), 61-68.

13. White, J. A., Todd, P. A., Rosenthal, A. N., Yee, J. L., Grant, R., \& Lerche, N. W. (2009). Development of a generic real-time PCR assay for simultaneous detection of proviral DNA of simian Betaretrovirus serotypes 1, 2, 3, 4 and 5 and secondary uniplex assays for specific serotype identification. Journal of virological methods, 162(1-2), 148-154.

14. Etienne, L., Eymard-Duvernay, S., Aghokeng, A., Butel, C., Monleau, M., \& Peeters, M. (2013). Single real-time reverse transcription-PCR assay for detection and quantification of genetically diverse HIV-1, SIVcpz, and SIVgor strains. Journal of clinical microbiology, 51(3), 787-798.

15. Matusali, G., Dereuddre-Bosquet, N., Le Tortorec, A., Moreau, M., Satie, A. P., Mahé, D., ... \& Dejucq-Rainsford, N. (2015). Detection of simian immunodeficiency virus in semen, urethra, and male reproductive organs during efficient highly active antiretroviral therapy. Journal of virology, 89(11), 5772-5787.

16. Khan, I. H., Mendoza, S., Yee, J., Deane, M., Venkateswaran, K., Zhou, S. S., ... \& Luciw, P. A. (2006). Simultaneous detection of antibodies to six nonhuman-primate viruses by multiplex microbead immunoassay. Clinical and vaccine immunology, 13(1), 45-52.

17. Ambrosino, E., Dumoulin, C., Orlandi-Pradines, E., Remoue, F., Toure-Baldé, A., Tall, A., ... \& Rogier, C. (2010). A multiplex assay for the simultaneous detection of antibodies against 15 Plasmodium falciparum and Anopheles gambiae saliva 
antigens. Malaria journal, 9(1), 1-12.

18. Liao, Q., Guo, H., Tang, M., Touzjian, N., Lerche, N. W., Lu, Y., \& Yee, J. L. (2011). Simultaneous detection of antibodies to five simian viruses in nonhuman primates using recombinant viral protein based multiplex microbead immunoassays. Journal of virological methods, 178(1-2), 143-152.

19. Perry, M. D., Corden, S. A., \& Howe, R. A. (2014). Evaluation of the Luminex xTAG Gastrointestinal Pathogen Panel and the Savyon Diagnostics Gastrointestinal Infection Panel for the detection of enteric pathogens in clinical samples. Journal of medical microbiology, 63(11), 1419-1426.

20. Dunbar, S. A., Ritchie, V. B., Hoffmeyer, M. R., Rana, G. S., \& Zhang, H. (2015). Luminex ${ }^{\circledR}$ Multiplex Bead Suspension Arrays for the Detection and Serotyping of Salmonella spp. In Salmonella (pp. 1-27). Humana Press, New York, NY

21. Munro, S. B., Kuypers, J., \& Jerome, K. R. (2013). Comparison of a multiplex real-time PCR assay with a multiplex Luminex assay for influenza virus detection. Journal of clinical microbiology, 51(4), 1124-1129.

22. Bai, X., Liu, Z., Ji, S., Gottschalk, M., Zheng, H., \& Xu, J. (2015). Simultaneous detection of 33
Streptococcus suis serotypes using the luminex xTAG ${ }^{\circledR}$ assay ${ }^{\mathrm{TM}}$. Journal of microbiological methods, 117, 95-99.

23. Navidad, J. F., Griswold, D. J., Gradus, M. S., \& Bhattacharyya, S. (2013). Evaluation of Luminex xTAG gastrointestinal pathogen analyte-specific reagents for high-throughput, simultaneous detection of bacteria, viruses, and parasites of clinical and public health importance. Journal of clinical microbiology, 51(9), 3018-3024.

24. Dunbar, S. A. (2006). Applications of Luminex® хМАРтм technology for rapid, high-throughput multiplexed nucleic acid detection. Clinica chimica acta, 363(1-2), 71-82.

25. van Brunschot, S. L., Bergervoet, J. H., Pagendam, D. E., de Weerdt, M., Geering, A. D., Drenth, A., \& van der Vlugt, R. A. (2014). Development of a multiplexed bead-based suspension array for the detection and discrimination of pospiviroid plant pathogens. PloS one, 9(1), e84743.

26. Wang, H., \& Wei, Q. (2015). Dynamic monitoring of virus antibody during the establishment of SPF cynomolgus monkey population. Acta Laboratorium Animalis Scientia Sinica, (6), 573577.

Cite this Article: Zhu-hong Liu et al (2021). A Multiplex Assay for Simultaneous Detection of Three Retroviruses in Nonhuman Primates Based on the Luminex xTAG Platform. EAS J Vet Med Sci, 3(2), 8-14. 